\title{
Leader Network Centrality and Team Performance: Team Size as Moderator and Collaboration as Mediator
}

\author{
Yingjie Yuan $^{1}$ (D) Daan van Knippenberg ${ }^{2}$
}

Accepted: 9 March 2021 / Published online: 24 March 2021

(C) The Author(s) 2021

\begin{abstract}
The social network perspective provides a valuable lens to understand the effectiveness of team leaders. In understanding leadership impact in team networks, an important question concerns the structural influence of leader centrality in advicegiving networks on team performance. Taking the inconsistent evidence for the positive relationship of network centrality and leadership effectiveness as a starting point, we suggest that the positive impact of leader centrality in advice-giving networks is contingent on team needs for leadership to meet communication and coordination challenges, which we argue are larger in larger teams. Developing our analysis, we examine the mediating role of member collaboration in the relationship of leader network centrality and team performance as moderated by team size. Based on a multi-source dataset of 542 employees and 71 team leaders, we found that leader centrality in advice-giving networks related positively to team performance in larger teams but negatively in smaller teams. Results supported the mediated moderation model via member collaboration in smaller teams, but not in larger teams.
\end{abstract}

Keywords Team leadership $\cdot$ Centrality $\cdot$ Advice-giving networks $\cdot$ Team size $\cdot$ Collaboration

The trend towards team-based organizations calls for the development of our understanding of team leadership (Day et al., 2006). Building on the long-standing recognition of leadership as embedded in social interactions within the team (Morgeson et al., 2010), and the notion that intrateam relational patterns involving leaders and members are complex and heterogeneous (van Knippenberg \& Mell, 2016), scholars have increasingly adopted the social network perspective to capture how a leader's network position affects leadership effectiveness in teams (Carson et al., 2007; Carter et al., 2015). This social network perspective complements other perspectives on team leadership such as behavioral-style approaches and shared leadership approaches (van Knippenberg, 2017), by uniquely capturing how a leader's position within the team network of social relationships influences leadership functioning. Network positions vary in their

Yingjie Yuan

yingjie.yuan@rug.nl

1 Department of Human Resource Management \& Organizational Behavior, Faculty of Economics and Business, University of Groningen, Nettelbosje 2, 9747AE, Groningen, The Netherlands

2 LeBow College of Business, Drexel University, Philadelphia, USA connectivity with other members and thus reflect how well positioned a leader is to effectively and efficiently influence team members when needed (Balkundi \& Kilduff, 2006; Balkundi et al., 2011; Carter et al., 2015; Sparrowe \& Liden, 2005).

In considering leaders' network positions, the emphasis is primarily on network centrality, the extent to which the leader is centrally positioned within the team's interaction patterns (Balkundi \& Harrison, 2006). For leadership, this is typically captured by the advice-giving network - the work-related flow of information, guidance, and advice from the leader to team members (Borgatti \& Everett, 2006; Kilduff \& Krackhardt, 2008). Centrality in advice-giving networks is of particular relevance to leadership effectiveness, because central positions in such information flows indicate direct and widespread task-related influence on team members (Sparrowe et al., 2001). Consistent with the notion that a vital task of team leadership is to supervise and regulate team functioning, scholars proposed a positive role for leader centrality in stimulating team performance (Balkundi \& Harrison, 2006; Balkundi \& Kilduff, 2006).

Building on this earlier work, we propose that the relationship between leader centrality in the team advice-giving network and team performance is contingent on team 
characteristics. The value of such a moderation perspective is corroborated by the inconsistent findings for the impact of leader centrality (Balkundi et al., 2011; Mehra et al., 2006). Network theories have indicated that the value of a network position is subject to the contextual characteristics of a given network (Borgatti \& Foster, 2003; Borgatti et al., 2009). The advantage of network centrality should be no exception in this respect. We identify team size as a fundamental influence on the benefits of leader centrality. Team size is a parsimonious indicator of the complexity of intrateam processes and communication (LePine et al., 2008). Teams with more complex communication patterns experience more process loss and have stronger needs for leadership guidance and interventions. Advice-giving centrality provides team leaders with a strategic position to quickly detect such needs and step in to guide team members. We therefore propose that leader centrality in advice-giving networks is more positively associated with team performance in larger teams, where intertwined interaction patterns and unwieldy communication benefit more from leadership interventions.

Further developing this analysis, we propose that member collaboration - the process of members working together to accomplish team tasks - mediates the interactive effect of leader centrality and team size (see Fig. 1 for the conceptual model). The merit of leader network centrality is more prominent in larger teams, where leaders can quickly detect problems in member coordination and foster member collaboration by providing guidance, developing shared understanding, and resolving tensions. Smaller teams, in comparison, tend to experience less process loss (e.g., communication and coordination challenges) and are more likely to address these challenges without regulation by team leaders. Accordingly, there is less benefit from leader centrality for member collaboration-leader centrality may even be disruptive to collaboration when it invites team members to concentrate communication on the team leader.

Social network analysis has advanced a powerful case for the importance of leader network centrality in promoting leadership effectiveness in teams (Carter et al., 2015). At the same time, inconsistent findings within this stream of research invite more attention to when and how leader centrality affects team performance. Accordingly, the present study contributes to the development of the social network perspective on team leadership by identifying a key moderating influence in team size as a parsimonious yet fundamental indicator of team needs for leadership. The implications of this contingency view are broad-ranging in that they should extend to other team and contextual characteristics that reflect team needs for leadership. From a team-process perspective, our focus on member collaboration adds to the limited understanding of how leader centrality promotes team performance, which so far was primarily concerned with the mediating role of leadership perceptions (Balkundi et al., 2011).

\section{Leader Centrality in Advice-Giving Networks and Team Performance}

As one of the most relevant networks to team functioning and performance (Kilduff \& Krackhardt, 2008; Sparrowe et al., 2001), advice networks refer to interpersonal communication flows about work-related problems in organizations. In principle, advice networks refer to two distinct flows. The information flow of providing team members task-related suggestions (i.e., advice-giving) reflects help-giving actions and implies interpersonal influence. In counterpoint to this, receiving advice suggests the flow of dependence, obligation, and vulnerability in interpersonal connections (Soltis et al., 2013; Zagenczyk \& Murrell, 2009). Whereas earlier research often did not specify advice-giving or advice-receiving in operationalizations, recent social network research has increasingly emphasized the importance of this distinction (Agneessens \& Wittek, 2012; Hayat \& Mo, 2015; Soltis et al., 2013). In leadership research, advice-giving is conceptually more relevant because of its close association with the leadership role in teams. Prior studies operationalized such advice-giving flows as incoming of advice-seeking ties (e.g., Balkundi \& Harrison, 2006). Because incoming adviceseeking ties do not equate to advice-giving (one can be asked for advice but not give it), in the present study, we assess advice-giving ties directly.
Fig. 1 Conceptual model of leader centrality and team size on team performance

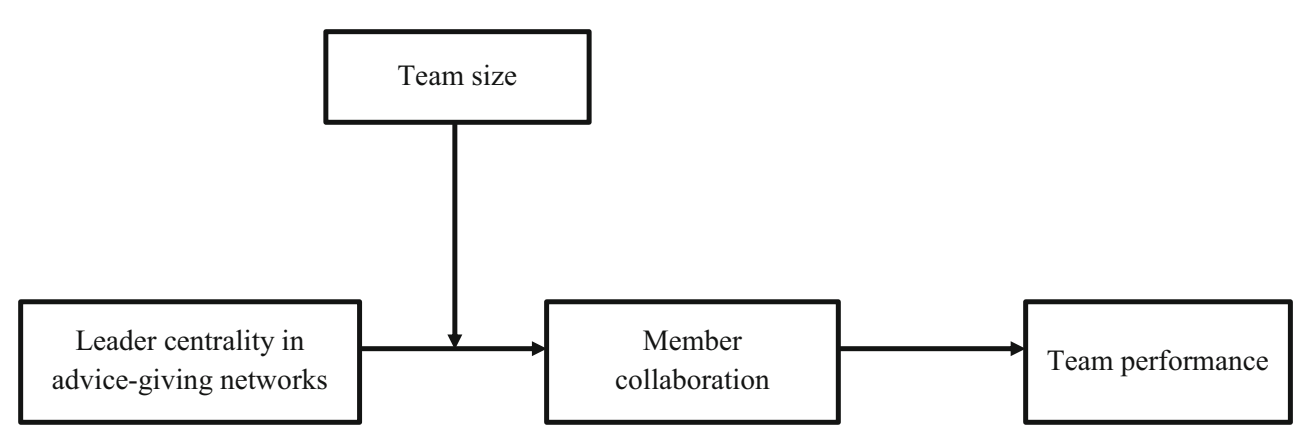


Centrality in advice-giving networks captures not just the number of advice ties that one has; it is also an indicator of influence. Providing work-related information, guidance, and advice to others in effect positions one to influence others. Accordingly, the more central one's position in the team's advice-giving network, the more influential one is within the team. Centrality in the advice-giving network reflects a strategic position to directly communicate with team members about work-related issues and to shape the way they handle those issues. Considering that one primary responsibility for team leaders is to direct and support members in team tasks whenever needed (Day et al., 2006; Stewart, 2006), centrality in the advice-giving network represents a positional advantage. As the leader is more central in the advice-giving network, (s)he possesses more direct and influential channels to communicate task objectives, to distribute resources and support, to address conflicts, and to motivate team members. In addition, centrality in the advice-giving network gives rise to perceptions of reputation and impact (Ibarra \& Andrews, 1993). This signaling effect also fosters positive responses to leaders with high centrality and enhances the effectiveness of leadership interventions (Balkundi et al., 2011).

In a meta-analytic review, Balkundi and Harrison (2006) summarized 13 effect sizes across different types of leader centrality (from advice-seeking networks to friendship networks) and established a positive link between leader network centrality and team performance. This finding inspired followup research to advance our understanding of this link focusing on centrality in the advice network. The evidence for the impact of leader centrality in the advice-giving network from these studies is inconsistent, however. Whereas some studies found a positive relationship between advice centrality and leadership effectiveness (Balkundi et al., 2009; Balkundi et al., 2011), other studies found no relationship (Mehra et al., 2006; Venkataramani et al., 2016). This begs the question of moderation in this relationship, which has only been addressed at the dyadic level (leader-follower relationships) and not at the team level. Venkataramani et al. (2016) found that leader centrality only stimulated employee voice to the extent that the subordinate was central in the network. Their finding is important to the present discussion because it supports the contingency perspective on the effect of leader centrality. Yet, it did not address effects on team outcomes, which cannot be extrapolated from these findings given that centrality is a relative judgment.

The essence of team leadership lies in satisfying a team's needs to enhance team effectiveness (Day et al., 2006; Morgeson et al., 2010). Team leaders are expected to address a variety of team needs, such as establishing shared identities (Hogg et al., 2012; van Dick et al., 2018), creating collective understandings (e.g., transactive memory systems (Bachrach et al., 2019), coordinating knowledge exchange and communication (Boies et al., 2015; Lee et al., 2010), and integrating inputs from different members (Shin \& Zhou, 2007). The strategic value of a central position in the team social network helps leaders enact these leadership roles effectively and efficiently. From the contingency perspective of leadership, the value of network centrality is reduced when teams have less need for such leadership. For instance, having team leaders in the center of team decision-making is a blessing when team members experience communication problems and conflicts, but may add very little when team communication is smooth and self-organized (Hollenbeck et al., 2011; Nederveen Pieterse et al., 2019). This points to the moderating role of factors reflecting the complexity of team communication and coordination and its associated need for leadership involvement. We identify team size as a fundamental influence in this aspect.

\section{The Moderating Role of Team Size}

Possibly the most basic and fundamental influence on the complexity of communication in teams is team size (Kerr, 1989; Latané et al., 1979; Poulton \& West, 1999). Resources such as expertise, social capital, and diverse perspectives of team members accumulate as team size grows (Guzzo \& Shea, 1992). Yet communication problems and the need for leadership intervention also develop in teams as team size grows (Campion et al., 1996). Research showed that in comparison to members of smaller teams, members of larger teams tend to be less motivated to participate in team activities (Peltokorpi \& Hasu, 2014), less engaged in team decision-making (Curral et al., 2001), more likely to experience task and relational conflicts (Amason \& Sapienza, 1997), and more prone to form subgroups and cliques (Carton \& Cummings, 2012). Members of smaller teams are often more cohesive and more satisfied with team experiences (Haleblian et al., 1993). Arguably, a key commonality underlying all these effects is that effective communication and coordination are more challenging for larger teams. As teams grow leaders, it is increasingly difficult to effectively communicate to all members, and there is a growing tendency for members to disengage from team communication. Thus, communication and coordination to support collaboration become more challenging in larger teams.

We propose, therefore, that the relationship between leader centrality in the advice-giving network and team performance is more positive in larger teams. Larger teams with more complex communication challenges have a stronger need for leadership to coordinate and support collaboration across different phases of teamwork. In earlier phases, larger teams have more need for leadership to bring together team members for discussion and communication (Pearce \& Herbik, 2004), to create shared understandings of team objectives and task requirements, and to organize and mobilize different types of resources. In later phases, larger teams benefit more from 
leaders motivating members, smoothing out social interactions, and retaining commitment and satisfaction among team members (Poulton \& West, 1999). A central position in the advice-giving network allows leaders to quickly detect such needs and offer guidance and input when and where needed. This advantage of central positions thus facilitates the fulfillment of leadership functions.

Smaller teams, in contrast, have less need for leadership, because members can more easily communicate with all other members to identify task problems, evaluate ongoing activities, and make corrections. Members are also more easily monitored in smaller teams, reducing the opportunity to disengage from the team process. Even when needed, leaders are relatively reachable regardless of their network positions due to the smaller size of communication networks. This renders a central position of team leaders less important for team members to effectively coordinate and collaborate. When smaller teams can effectively meet challenges without the team leader stepping in, leader centrality in the advice-giving network may to some extent even disrupt team collaboration. Leaders in the center of communications may obstruct direct communication among team members, because communication among team members can be weakened by a tendency to prioritize communication with the leader (Brass \& Burkhardt, 1993; Leenders et al., 2003). What this in effect means is not only that leader network centrality has a less positive influence on team coordination and performance in smaller teams but also that this influence may be negative for smaller teams. Thus, we propose:

Hypothesis 1: Team size moderates the relationship between leader centrality in the advice-giving network and team performance, such that leader centrality is more positively related to team performance as teams are larger.

\section{Mediated Moderation Model via Member Collaboration}

Understanding the influence of leader network centrality with our focus on contextual needs for leadership also requires attention to the next issue - the mediating mechanism involved. Our understanding of the mechanism mediating between leader network centrality and team performance is underdeveloped (Carter et al., 2015). Empirical tests of how leader centrality affects team outcomes are scarce. Balkundi et al. (2011) presented a perceptual model to explain that the positional advantage of leader centrality evoked positive perceptions of leader charisma in subordinates, which would lead to more positive responses to a leader's behaviors or suggestions. This provides a basis to understand the influence of leader centrality from the perspective of subordinate perceptions. Yet, as relevant as more positive perceptions of the leader are, they do not capture the team process through which leader centrality affects team outcomes. We identify member collaboration as the mediating process explaining the effect of leader centrality on team performance as moderated by team size.

Member collaboration refers to the collective process of members transforming team inputs into team products (LePine et al., 2008; Reagans \& Zuckerman, 2001; Zaccaro et al., 2001). Organizational research has established a positive link between member collaboration and team performance (Bedwell et al., 2012; LePine et al., 2008; Marks et al., 2001). In a collaborative team, individual members are prone to share task understandings and strive together to achieve team goals. When members are less collaborative, individual endeavors are dispersed and less integrated. As a result, it impairs the synergistic process of combining diverse resources into team products.

We propose that member collaboration mediates the interactive effect of leader centrality and team size on team performance. As outlined in the previous section, leader centrality provides a positional benefit for leaders to quickly detect issues and to guide and motivate team members in larger teams. These benefits of leader centrality obtain more for larger teams, where the communication and coordination among team members are more challenging and raise greater needs for leadership guidance. As a result, there is greater value in team leaders being well positioned in larger teams. The issue here is much more than enacting leadership behaviors to directly affect individual members' behaviors. Rather, because larger teams struggle more with creating shared understandings of teamwork that is the cornerstone of collaborative efforts (Amason \& Sapienza, 1997; Wong, 2004), network centrality in larger teams enables leaders to build shared views of team objectives and member roles and to develop unitary teamwork processes. Core to team performance are the coordinated collaborative efforts of team members. Leaders more central in the network of larger teams are better positioned to stimulate such collaboration both by fostering shared understandings for collaboration and by stepping in to help solve problems that individual members meet.

Smaller teams, in contrast, typically experience fewer communication and coordination problems. A major reason is that members in smaller teams can easily and frequently communicate with each other. Accordingly, smaller teams are in less need of team leaders to develop shared understandings and meet challenges. There would still be a role for such leadership, but the benefits of leader centrality in fostering member collaboration are less prominent in smaller teams where it is easier for members to self-organize collaborative efforts. Moreover, there can also be a downside to leader centrality in smaller teams in that the more employees receive information and advice from leaders, the less likely they are to seek 
inputs elsewhere in the team (Kratzer et al., 2008). The fewer benefits there are to leader centrality, the greater the risk that leader centrality could even be counterproductive in reducing the communication among members that lies at the foundations of member collaboration. We thus propose:

Hypothesis 2: Member collaboration mediates the interaction effect of leader centrality in the advice-giving network and team size on team performance.

\section{Method}

\section{Data and Sample}

Data were collected from seventy-five franchised stores of a bakery group located in central China. These seventy-five franchise stores shared the same performance environment: Each store functioned independently as a team and took full responsibility for its performance. Store managers as team leaders closely monitored and regulated team activities to meet performance requirements and customer needs. This setting qualified for our research aim to observe the impact of leader centrality on team performance.

To avoid common source bias, we sent out paper-andpencil questionnaires to employees and team leaders (i.e., store managers) respectively in two time slots. Five research assistants first administered surveys to team members on-site and collected them right away to ensure the confidentiality of employee responses. Two weeks later, one author distributed questionnaires to all team leaders during a monthly review meeting in the headquarter office. Reminders were sent to absent employees and leaders in the following week. In total, 567 out of 577 employees filled out the subordinate questionnaire, and 73 out of 75 team leaders filled out the supervisors' counterparts. After matching two waves of data, we dropped two teams with incomplete supervisor responses (a team of 14 members and a team of 6 members) and 5 incomplete subordinate responses. The final sample consisted of $542 \mathrm{em}-$ ployees and 71 team leaders from 71 teams. Team size ranged from 4 to 22 members $\left(M_{\text {size }}=8.67, S D_{\text {size }}=3.27\right)$.

\section{Measures}

Both leader and subordinate surveys were provided in Chinese. We went through a back-translation process to ensure validity across languages (Brislin, 1970). One author first translated all items into Chinese. Then two native Chinese graduate students blind to the purpose and content of this study translated them back into English and compared them against the original. We found a high level of consistency in the translation. This ensured that the Chinese items were equivalent to the original ones.

Leader Centrality We measured leader centrality with the widely adopted roster method (Perry-Smith, 2006). Each employee received a name list of all coworkers (including the team leader) to rate their advice-giving to each ratee on a 6point Likert scale ( $1=$ "less often than several times a year", 2 $=$ "several times a year", $3=$ "once a month", $4=$ "several times a month", $5=$ "several times a week", $6=$ "daily"). The question was "To what extent do you give professional advice to this person when s/he has work-related problems?" The response rate per team varied from 71.4 to $100 \%$, with merely two teams below $80 \%$. These high response rates satisfied the minimum requirement of $70 \%$ (Borgatti et al., 2006) and allowed us to conduct social network analysis with sufficient credibility. We operationalized leader centrality as Bonacich's power centrality (positive beta centrality). This index of power centrality accounts for the centrality of team leaders' connections in the advice network (Bonacich, 1987) and has been recognized as superior to Freeman's degree centrality measure in capturing the central role and information impact of individual members relative to the rest of the team (Borgatti et al., 2002). It was often adopted in prior leadership research (e.g., Mehra et al., 2006).

Team Performance Two weeks after the subordinate survey, team leaders rated team performance in the previous fiscal season with four items on a 10-point scale from "not at all" to "extremely well": (1) the overall quality of teamwork, (2) the work efficiency as a team, (3) the punctuality of teamwork, and (4) performance requirements on each sales season. These four items were adapted indigenously from Mohammed and Nadkarni's (2011) measure of team performance and validated through our interviews on executive management (e.g., chief operation officers). Cronbach's alpha was 0.71 .

Member Collaboration Due to the shared working environment and frequent contacts with team members on a daily basis, team leaders were capable of assessing how members worked together to meet team requirements. This was also confirmed in our pre-survey interviews on executive management. We used a single-item measure developed with reference to Zhu et al.'s (2018) intrateam collaboration measure for member collaboration, on a 10-point scale from "not at all" to "extremely well." The item was "Team members collaborate to accomplish team tasks together." The content validity of single-item measures for team collaboration has been evidenced in prior team research (Cha et al., 2015), consistent with claims from methodologists that single-item measures are not inferior to multi-item measures (Gardner et al., 1998) and could provide sufficient construct validity and reliability (Rossiter, 2008; Rousseau \& Tijoriwala, 1998). 
Control Variables We controlled for three factors that might influence the relationship between leader centrality and team performance. First, we controlled for average individual performance to underline the unique impact of leader centrality on team performance, recognizing that bringing together high performers naturally increases team performance (Klein \& Kozlowski, 2000; Kozlowski \& Klein, 2000). Team leaders rated the individual performance of each subordinate on four aspects of employee performance: (1) job obligations and requirements, (2) punctuality on work tasks, (3) work quality, and (4) conformity to norms and regulations. Cronbach's alpha was 0.82 . Second, we controlled for average member conscientiousness, which was concluded in previous metaanalytic reviews to predict team performance (Peeters et al., 2006). Third, considering that team tenure is predictive of the number and strength of social ties individual members have (Mehra et al., 2001; Reagans \& Zuckerman, 2001) and thus can reflect member influence in advice networks, we controlled for average team tenure of individual members for a more accurate view of leader centrality and its impacts.

Discriminant Validity and CFA Models Because team leaders reported both member collaboration and team performance, we conducted a confirmatory factor analysis to test the discriminant validity of these two measures. The two-factor model (member collaboration and team performance as two separate factors) showed a good fit with the data $\left(\chi^{2}=2.50, d f=4\right.$; $\mathrm{CFI}=1.00$; RMSEA $=0.00$, SRMR $=0.03$ ), with all items loading significantly on their intended factors. Compared with the one-factor model in which all items loaded onto one latent variable $\left(\chi^{2}=8.76, d f=5 ; \mathrm{CFI}=0.96\right.$; $\mathrm{RMSEA}=0.10$, SRMR $=0.06)$, the two-factor model was significantly superior $\left(\chi^{2}(1)\right.$ $=6.26, p<.05)$. This supported our operationalizations of member collaboration and team performance as distinct variables.

\section{Results}

Table 1 shows the descriptive statistics and correlations of variables in this study.

\section{Hypotheses Testing}

We tested hypothesis 1 in a hierarchical regression. In support for hypothesis 1 , we found an interaction between leader centrality and team size in shaping team performance $\left(\Delta R^{2}\right.$ $=0.10, b=0.15, t=2.95, p<.01,95 \% \mathrm{BCa} \mathrm{CI}=[0.05$, $0.25]$ ). The overall moderation model explained $29 \%$ of the variance in team performance (see Table 2 and Fig. 2).

To capture how the relationship between leader centrality and team performance varied as a function of team size, we probed the regions of significance for this effect with Johnson and Neyman's (1936) technique (Preacher et al., 2006). We used Tan's (2015) R package 'probemod' for this analysis. As shown in Table 3, leader centrality was positively related to team performance when team size was larger (11 and above), but negatively related to team performance when team size was smaller ( 7 and below).

Next, we tested the mediated moderation model (hypothesis 2) with the R package "mediation" (Tingley et al., 2014). This method allowed us to identify indirect effects at specific values of the moderator. Following MacKinnon et al.'s (2004) suggestion, we used the bias-corrected bootstrapping simulation method to construct confidence intervals for indirect effects.

Hypothesis 2 predicted that member collaboration mediated the joint impact of leader centrality and team size on team performance. As shown in Table 4, the impact of the leadercentrality-by-team-size interaction decreased after the inclusion of member collaboration. Our analysis of mediated moderation showed only a weak indication of an indirect effect across all levels of team size (ACME $=-0.07,95 \% \mathrm{BCa} C \mathrm{CI}=$ $[-0.20,0.02], p=.1)$. Considering that we anticipated that the effect of centrality may not be positive across all team sizes (possibly negative in smaller teams), the average causal mediated effect across all team sizes might not reveal an accurate view for testing hypothesis 2 . Thus, we analyzed conditional indirect effects of leader centrality on different regions of team sizes, in line with the significant regions detected above. In line with predictions, in smaller teams ( 7 members and less), the average causal mediated effect (ACME) was negative $(\mathrm{ACME}=-0.13,95 \% \mathrm{BCa} \mathrm{CI}=[-0.29,-0.02], p=.04) . \mathrm{In}$ larger teams (11 members and more), the average causal mediated effect (ACME) was positive but nonsignificant (ACME $=0.39,95 \% \mathrm{BCa} \mathrm{CI}=[-0.66,1.11], p=.49)$. Thus, hypoth esis 2 was only supported in the conditional indirect effect for smaller teams but not for larger teams.

\section{Supplementary Analysis of Leader Advice-Receiving Centrality}

We focused on advice-giving networks to study leader positions for leadership effectiveness, for it is the advice-giving network that captures how leaders exert influence and regulations. Advice-receiving networks, on the contrary, reflect dependency and lack of influence. In this supplementary analysis, we complemented our conceptual focus on advice-giving networks with an analysis of advice-receiving networks. We anticipated that the effect of leader advice-receiving centrality would follow a different pattern and that our prediction of leader advice-giving centrality would hold when taking the advice-receiving centrality into account.

We measured advice-receiving ties using the same approach as for advice-giving. Team members reported on each co-worker including the team leader, "To what extent do you 
Table 1 Descriptive statistics and inter-correlations among study variables ${ }^{\mathrm{a}}$

\begin{tabular}{|c|c|c|c|c|c|c|c|c|}
\hline Variables & Mean & S.D. & 1 & 2 & 3 & 4 & 5 & 6 \\
\hline 1. Team performance & 7.65 & 1.17 & - & & & & & \\
\hline 2. Leader centrality in advice-giving networks & 0.98 & 0.20 & -0.08 & - & & & & \\
\hline 3. Team size & 8.65 & 3.29 & 0.03 & -0.06 & - & & & \\
\hline 4. Member collaboration & 8.73 & 1.45 & $0.64^{* * * * *}$ & -0.13 & -0.13 & - & & \\
\hline 5. Average member performance & 7.33 & 0.98 & $0.40^{* * * *}$ & 0.06 & 0.02 & $0.32^{* *}$ & - & \\
\hline 6. Average member conscientiousness & 7.23 & 0.57 & 0.12 & -0.02 & -0.19 & $0.21^{\dagger}$ & 0.14 & - \\
\hline 7. Average team tenure & 1.10 & 0.38 & 0.12 & -0.17 & -0.14 & 0.09 & 0.06 & -0.15 \\
\hline
\end{tabular}

${ }^{\mathrm{a}} N=71$

${ }^{\dagger} p<.1$

${ }^{*} p<.05$

${ }^{* * *} p<.01$

**** $p<.001$

receive professional advice from this person when having using otherwise the same predictors as for our primary analywork-related problems?" Results of a regression analysis

Table 2 Regression results of hypothesis 1 and supplementary analysis ${ }^{\mathrm{a}}$

\begin{tabular}{|c|c|c|c|c|c|}
\hline \multirow[t]{2}{*}{ Variables } & \multirow[t]{2}{*}{$R^{2}$} & \multirow[t]{2}{*}{$B$} & \multirow[t]{2}{*}{$t$} & \multicolumn{2}{|c|}{$95 \%$ CIs } \\
\hline & & & & Lower & Upper \\
\hline \multicolumn{6}{|l|}{ Hypothesis 1 (leader advice-giving centrality as a predictor) } \\
\hline Constant & & 7.43 & $20.60^{* * * *}$ & 6.71 & 8.15 \\
\hline Average member performance & & 0.40 & $3.20 * *$ & 0.15 & 0.66 \\
\hline Average team tenure & & 0.12 & 0.96 & -0.13 & 0.38 \\
\hline Average member conscientiousness & & 0.07 & 0.54 & -0.19 & 0.33 \\
\hline Leader centrality in advice-giving networks & & -1.30 & $-3.05^{* *}$ & -2.15 & -0.45 \\
\hline Team size & & 0.03 & 0.72 & -0.05 & 0.11 \\
\hline Leader centrality $\times$ team size & & 0.15 & $2.95^{* *}$ & 0.05 & 0.25 \\
\hline$\Delta R^{2}$ & $0.10^{* *}$ & & & & \\
\hline$R^{2}$ & $0.29^{* *}$ & & & & \\
\hline \multicolumn{6}{|l|}{ Supplementary analysis (leader advice-receiving centrality as a predictor) } \\
\hline Constant & & 7.01 & $16.58^{* * * *}$ & 6.16 & 7.85 \\
\hline Average member performance & & 0.45 & $3.51^{* * * *}$ & 0.19 & 0.71 \\
\hline Average team tenure & & 0.13 & 0.96 & -0.14 & 0.39 \\
\hline Average member conscientiousness & & 0.16 & 1.19 & -0.11 & 0.43 \\
\hline Leader centrality in advice-receiving networks & & 0.63 & 1.21 & -0.41 & 1.68 \\
\hline Team size & & 0.08 & $1.67^{\dagger}$ & -0.02 & 0.18 \\
\hline Leader centrality $\times$ team size & & -0.10 & $-1.71^{\dagger}$ & -0.23 & 0.02 \\
\hline$\Delta R^{2}$ & $0.03^{\dagger}$ & & & & \\
\hline$R^{2}$ & $0.25^{* *}$ & & & & \\
\hline \multicolumn{6}{|c|}{ Supplementary analysis (advice-giving centrality with advice-giving centrality subtracted) } \\
\hline Constant & & 6.93 & $17.73^{* * * *}$ & 6.16 & 7.85 \\
\hline Average member performance & & 0.38 & $3.08^{* *}$ & 0.19 & 0.71 \\
\hline Average team tenure & & 0.18 & 1.44 & -0.14 & 0.39 \\
\hline Average member conscientiousness & & 0.16 & 1.29 & -0.11 & 0.43 \\
\hline Leader centrality in advice-giving networks (advice-receiving subtracted) & & -1.00 & $-2.56^{*}$ & -0.41 & 1.68 \\
\hline Team size & & 0.10 & $2.21^{*}$ & -0.02 & 0.18 \\
\hline Leader centrality $\times$ team size & & 0.13 & $3.35^{* *}$ & -0.23 & -0.02 \\
\hline$\Delta R^{2}$ & $0.12^{* *}$ & & & & \\
\hline$R^{2}$ & $0.32^{* * * *}$ & & & & \\
\hline \multicolumn{6}{|l|}{${ }^{\mathrm{a}} N=71$} \\
\hline \multicolumn{6}{|l|}{${ }^{* * * *} p<.001$} \\
\hline \multicolumn{6}{|l|}{${ }^{* *} p<.01$} \\
\hline${ }^{\dagger} p<.1$ & & & & & \\
\hline
\end{tabular}




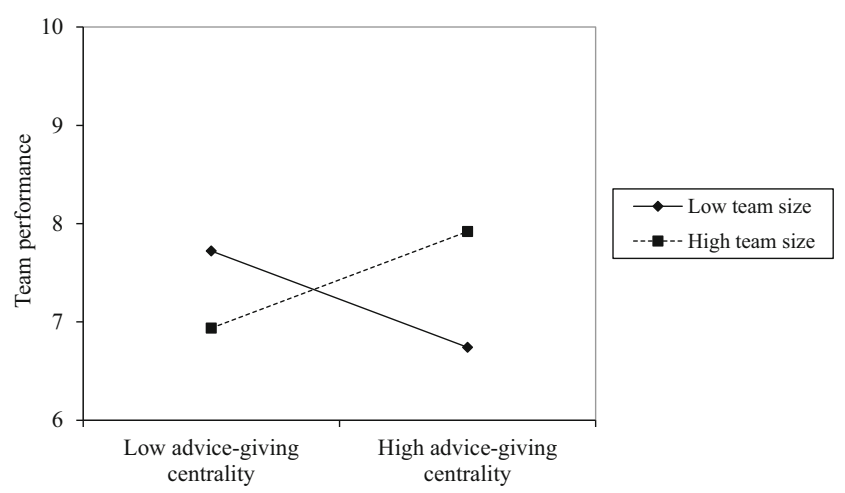

Fig. 2 Interaction effect of leader's advice-giving centrality and team size on team performance (hypothesis 1)

leader centrality in the advice-receiving network and team size on team performance $(b=-0.10, t=-1.71, p<.1,95 \% \mathrm{BCa} C \mathrm{CI}$ $=[-0.23,0.02]$; see Table 2). Thus, the findings for leader advice-receiving centrality in a sense mirror those for advice-giving, suggesting that where influence on the team is concerned, advice-receiving reflects the opposite of advicegiving - and thus corroborating our conceptual argument for the focus on advice-giving.

Table 3 Conditional effect of leader network centrality on team performance (hypothesis 1)

\begin{tabular}{|c|c|c|c|c|}
\hline \multirow[t]{2}{*}{ Team size } & \multirow[t]{2}{*}{$B$} & \multirow[t]{2}{*}{$t$} & \multicolumn{2}{|c|}{$95 \%$ confidence interval } \\
\hline & & & Lower & Lower \\
\hline 4 & -0.71 & $-2.92^{* * * *}$ & -1.19 & -0.22 \\
\hline 5 & -0.56 & $-2.78^{* *}$ & -0.96 & -0.16 \\
\hline 6 & -0.41 & $-2.50^{*}$ & -0.74 & -0.08 \\
\hline 7 & -0.27 & $-1.92^{\dagger}$ & -0.54 & 0.01 \\
\hline 8 & -0.12 & -0.94 & -0.37 & 0.13 \\
\hline 9 & 0.03 & 0.22 & -0.24 & 0.30 \\
\hline 10 & 0.18 & 1.13 & -0.14 & 0.49 \\
\hline 11 & 0.32 & $1.71^{\dagger}$ & -0.06 & 0.70 \\
\hline 12 & 0.47 & $2.05^{*}$ & 0.01 & 0.93 \\
\hline 13 & 0.62 & $2.27^{*}$ & 0.07 & 1.17 \\
\hline 14 & 0.77 & $2.41^{*}$ & 0.13 & 1.40 \\
\hline 15 & 0.91 & $2.51^{* *}$ & 0.19 & 1.64 \\
\hline 16 & 1.06 & $2.58^{* *}$ & 0.24 & 1.89 \\
\hline 17 & 1.21 & $2.63^{* *}$ & 0.29 & 2.13 \\
\hline 18 & 1.36 & $2.67^{* *}$ & 0.34 & 2.37 \\
\hline 19 & 1.50 & $2.70^{* *}$ & 0.39 & 2.62 \\
\hline 20 & 1.68 & $2.73^{* *}$ & 0.45 & 2.91 \\
\hline 21 & 1.81 & $2.75^{* *}$ & 0.50 & 3.13 \\
\hline 22 & 1.95 & $2.77^{* *}$ & 0.54 & 3.35 \\
\hline $\begin{array}{l}{ }^{\dagger} p<.1 \\
{ }^{*} p<.05 \\
{ }^{* *} p<.01\end{array}$ & & & & \\
\hline
\end{tabular}

In a second analysis, we subtracted leader advice-receiving centrality from the advice-giving centrality measure for a robustness test. Results of the moderation analysis revealed consistent findings as in our primary analysis (see Table 2): This alternative advice centrality measure positively interacted with team size $(b=0.13, t=3.29, p<.01,95 \% \mathrm{BCa} \mathrm{CI}=$ $[0.05,0.20])$, with the entire model explaining $32 \%$ of the variance.

\section{Supplementary Analysis of Collective Leadership in Advice-Giving Networks}

As noted in the Introduction, the current focus on the network centrality of team leaders is not in opposition to other perspectives on team leadership; our focus on the role of the formal team leader is not to deny the influence of the collective shared leadership that team members may display. The leadership literature has long recognized that team members more or less engage in shared leadership in team functioning (Contractor et al., 2012; Day et al., 2006; Friedrich et al., 2009) and that shared leadership shapes team performance independent of formal leaders' influence (Nicolaides et al., 2014; Wang et al., 2014). Prior research approached shared leadership from a social network perspective and captured it in the decentralization of team networks (Carter et al., 2015; Contractor et al., 2012). In this supplementary analysis, we aimed to test the robustness of the effect of leader advice-giving centrality when controlling for shared leadership from the social network perspective.

In line with prior studies (Contractor et al., 2012), we captured collective leadership as the decentralization of the advice-giving network. Decentralized advice-giving networks suggest that advice influence disperses among team members, in contrast to centralized networks where the advice power concentrates on one or few individuals. First, we tested the influence of collective leadership on team performance. Results showed no main effect of collective leadership on team performance $(b=0.01, t=0.18, p>.1,95 \% \mathrm{BCa} \mathrm{CI}=$ $[-0.08,0.09])$, nor an interaction effect with team size $(b$ $=-.00, t=-0.13, p>.1,95 \% \mathrm{BCa} \mathrm{CI}=[-0.01,0.01])$. In a second analysis, we entered collective leadership and its interaction with team size as controls in a robustness test of hypothesis 1 . Results were consistent with our primary analysis, with a positive interaction between leader advice centrality and team size $(b=0.16, t=3.63, p<.001,95 \% \mathrm{BCa} C \mathrm{CI}=$ $[0.07,0.24])$. This supported the robustness of our findings.

\section{Discussion}

There is a growing appreciation of the strategic positions of leaders in team networks and possible impacts on team effectiveness (Balkundi et al., 2009; Carter et al., 2015; 
Table 4 Conditional indirect effects of leader centrality on team performance (hypothesis 2)

\begin{tabular}{|c|c|c|c|c|}
\hline & \multirow[t]{2}{*}{$B^{\mathrm{a}}$} & \multirow[t]{2}{*}{$t$} & \multicolumn{2}{|l|}{$95 \% \mathrm{CI}$} \\
\hline & & & LLCI & ULCI \\
\hline \multicolumn{5}{|l|}{ Total effect (DV: team performance) } \\
\hline Constant & 7.28 & $24.30^{* * *}$ & 6.69 & 7.86 \\
\hline Average member performance & 0.23 & $2.08^{*}$ & 0.01 & 0.44 \\
\hline Average team tenure & 0.09 & 0.81 & -0.12 & 0.29 \\
\hline Average member conscientiousness & -0.01 & -0.13 & -0.22 & 0.20 \\
\hline Leader centrality in advice-giving networks & -0.93 & $-2.59^{*}$ & -1.63 & -0.22 \\
\hline Team size & 0.05 & 1.43 & -0.02 & 0.11 \\
\hline Member collaboration (mediator) & 0.62 & $5.54^{* * * *}$ & 0.40 & 0.85 \\
\hline Leader centrality $\times$ team size & 0.11 & $2.70^{* *}$ & 0.03 & 0.19 \\
\hline \multicolumn{5}{|l|}{ Conditional indirect effect } \\
\hline Small teams (team size: $4-7$ ) & $-0.13^{*}$ & & -0.29 & -0.02 \\
\hline Large teams (team size: $11-22$ ) & 0.39 & & -0.66 & 1.11 \\
\hline \multicolumn{5}{|l|}{ Conditional direct effect } \\
\hline Small teams (team size: $4-7$ ) & -0.14 & & -0.31 & 0.16 \\
\hline Large teams (team size: $11-22$ ) & $1.55^{*}$ & & -0.10 & 2.57 \\
\hline \multicolumn{5}{|l|}{ Conditional total effect } \\
\hline Small teams (team size: 4-7) & $-0.27^{\dagger}$ & & -0.46 & 0.09 \\
\hline Large teams (team size: $11-22$ ) & $1.95^{\dagger}$ & & -0.44 & 3.16 \\
\hline \multicolumn{5}{|l|}{ Proportion mediated } \\
\hline Small teams (team size: $4-7$ ) & $0.48^{\dagger}$ & & -5.05 & 0.86 \\
\hline Large teams (team size: $11-22$ ) & 0.20 & & -22.53 & 0.21 \\
\hline $\begin{array}{l}N=71 . C I, \text { confidence intervals } \\
{ }^{* * * *} p<.001 \\
{ }^{* * *} p<.01 \\
{ }^{*} p<.05 \\
{ }^{\dagger} p<.1\end{array}$ & & & & \\
\hline
\end{tabular}

Oh et al., 2004). In this respect, leader centrality has been emphasized as the most important influence to consider (Balkundi \& Kilduff, 2006). Contributing to this emerging stream of research, we developed a model capturing moderation and mediation in the influence of leader centrality on team performance. We found that this relationship was more positive in larger teams than in smaller teams (hypothesis 1). We also found partial support for the mediating role of member collaboration in this moderated influence (hypothesis 2) - the conditional indirect effect was significant for smaller teams but not for larger teams. Two supplementary analyses spoke to the robustness of these findings by establishing the distinctiveness of leader advice-giving centrality from (1) leader advice-receiving centrality and from (2) collective leadership as reflected in the advice-giving network, and by showing the robustness of our findings when controlling for these other aspects of the advice network.

\section{Theoretical Implications}

The social network perspective offers insights to identify how a leader's position within the team network of relationshipsmost notably network centrality — affects leadership effectiveness (Kilduff \& Krackhardt, 2008; Klein et al., 2004; Krackhardt, 1999). Prior studies of leader network centrality advocated its positive effect (Balkundi et al., 2009; Balkundi $\&$ Kilduff, 2006). Since these seminal studies, however, the field has not advanced much beyond this posited main effect even in the face of inconsistent evidence for this effect. This is somewhat surprising considering the prevalent contingency view of team leadership effectiveness (Day et al., 2006; Zaccaro et al., 2001).

To advance this line of research, we developed a contingency approach and proposed that the effect of leader centrality should be understood from the perspective of team needs for leadership (Day et al., 2006; Zaccaro et al., 2001). We 
suggested that such needs for leadership in the substantive part can be linked to a fundamental team characteristic - team size. The importance of team size in team operations has been stressed for a long time already, even when team size only receives little empirical attention (Curral et al., 2001; Poulton $\&$ West, 1999). Our study underscores the value of team size in predicting leader centrality effects. The results of this study revealed that leader advice-giving centrality was only a positive influence on team performance in larger teams and can even compose a negative influence in smaller teams. This negative influence of leader centrality had not been documented before, but is consistent with other lines of research suggesting that a highly central member may block information flows among team members and impair performance (Hollenbeck et al., 2011; Pan et al., 2019).

Whereas the present study focused on team size as a key indicator of team needs for leadership, the implication of this underlying rationale is broader-ranging. Following a similar logic, many factors relating to team needs for leadership can be expected to affect the effectiveness of leader network centrality. Team diversity, for example, is predictive of team needs for leader interventions and thus highly relevant to the influence of leader centrality in teams. The CategorizationElaboration Model of team diversity stressed the conditional impact of team diversity (van Knippenberg et al., 2004). Team diversity may benefit team performance (Bell et al., 2011) and also stimulate task and relational conflicts among members (Hobman et al., 2003). Diverse teams may struggle with workflow issues and thus benefit more from leadership interventions (Kearney \& Gebert, 2009; Nederveen Pieterse et al., 2019). In a similar vein, Tröster et al. (2014) found that teams with higher cultural diversity benefited more from a centralized workflow network than less diverse teams. Despite the absence of leadership focus in their study, their interpretation in terms of a greater need for centralized coordination in more diverse teams is well aligned with our proposition here. This implies that linking the influence of leader network centrality with team diversity could be a valuable next step in addressing the broader implications of our analysis. It also invites researchers to consider other moderating factors of the relationship between a leader's network centrality and team performance that could feed into team communication and coordination challenges, and thus into team needs for leadership.

The implication of well-positioned team leaders can also be extended to other perspectives of team leadership in literature. Leadership functions in teams become manifest in various forms. Team leaders are expected not merely to provide guidance or suggestions when needed, but also to create shared identities and understandings in team members (Steffens et al., 2014) and to develop shared leadership and self-leadership (Stewart et al., 2019). The social network perspective concerning strategic leader positions can add value to these approaches too (Carter et al., 2015). For instance, the social identity perspective to team leadership emphasizes the benefit of group prototypical leaders as well as leaders cultivating collective identities in subordinates to motivate "collective self-determination" (Hogg et al., 2012; van Dick et al., 2018). This line of research has not been linked with the social network perspective. An intriguing direction for future studies may be to explore strategic network positions (e.g., network center, or brokerage) for leaders to effectively foster collective identity in teams.

Our finding that member collaboration mediated the relationship between leader centrality and team performance, albeit only for smaller teams, invites research to further explain the mechanisms through which leader centrality affects team performance. There are several conceptual discussions on this issue (Balkundi \& Kilduff, 2006; Balkundi et al., 2011; Kratzer et al., 2008; Mehra et al., 2006). Yet, to the best of our knowledge, Balkundi et al.' (2011) study was the only empirical study testing how leader network centrality affected team performance. They explained this with the signaling effect of leader centrality, such that subordinates tend to view more centrally positioned leaders as more charismatic and inspiring, and subsequently are more prone to accept and carry out leaders' instructions. We complement their focus on subordinate perceptions of leaders by focusing on behavioral processes as a mechanism involved in the effect of leader network centrality. A logical follow-up may be to integrate these two perspectives in a two-stage mediation process. That is, leader centrality may affect member collaboration not only because the central leaders alter how members communicate and collaborate in workflows but also because this position leads members to view team leaders more positively and thus be more open to their influence.

We should also consider that the mediating role of member collaboration was only found for smaller teams but not for larger teams. In larger teams, we did observe a positive effect of leader centrality, but it was not mediated by member collaboration. Given the conservative nature of null hypothesis significance testing, we would be hesitant to dismiss the notion of team collaboration mediating the positive effects of leader network centrality. Nevertheless, it is useful to speculate about alternative mechanisms that may have played a role here. In that respect, we may draw on the notion that leader centrality can also reduce team collaboration, as per our findings for smaller teams and the evidence that centralized communication may discourage communication with less central team members (Brass \& Burkhardt, 1993; Leenders et al., 2003). The positive role of leader centrality may be less about stimulating collective positive behaviors (such as member collaboration) without the direct involvement of team leaders, but more about resolving conflicts among members (Babalola et al., 2018). Future research would have to speak to the merits of these considerations, but the fact that we did not find full support for our mediation model at least suggests that it is 
valuable to further explore alternative mediating processes in future research.

\section{Practical Implications}

By speaking to the positive and negative influence of leader network centrality, our study also has managerial implications. Team leaders can actively seek advice-giving roles in the team network of social interactions. Whereas earlier studies advised team leaders to strive for central positions in the advice-giving network, our results suggest that leaders may either want to build a central position in the team's advicegiving network or to avoid taking such a central position. Our findings show that leader network centrality is beneficial in larger teams but detrimental in smaller teams. This influence holds regardless of the collective leadership among team members. Although the cut-off point of larger (11 members and more) versus smaller teams ( 7 members and less) in this study should not be taken as absolute, the implication is clear that teams benefit when leaders take team size into account in determining how they position themselves within the team's advice-giving network.

In a broader sense, our findings suggest that managers should carefully consider team needs in determining how to position themselves in team social networks - to what extent the team is likely to experience communication and coordination challenges and desires external leadership interventions. Depending on the extent to which such team needs seem likely, team leaders may consider building a more central or peripheral position in the advice-giving flows of teams. By implication, organizations may also consider taking such considerations on board in leadership development programs to help leaders leverage their network positions. The social network approach also provides a powerful tool for managers to accurately detect their network positions and obtain actionable insights to identify when and how to intervene.

\section{Limitations and Future Directions}

As in all research, the choices made in this study come with some limitations that invite future research. First, our study is correlational and does not establish causality. Ideally, future work would include field experiments with interventions targeted at leader centrality (i.e., as per our implications for practice, leaders can to some extent actively shape their network positions) to establish causality and to rule out the influence of other variables that may covary with network centrality.

Second, our measure of member collaboration is not ideal. Having both member collaboration and team performance rated by team leaders might inflate this relationship, even when CFA evidence supported the distinction between these two variables. We followed the network tradition to measure collaboration with one item (Uzzi \& Spiro, 2005). Future studies could employ multi-item measures that may be more robust in capturing collaboration. For team performance, future research would ideally draw on more objective company assessments of team performance from, for instance, corporate performance management. This would reduce common source biases and address the issue we turn to nextsocial-desirability bias in survey responses.

We may also note that we administered the survey to all team leaders during a monthly review meeting in the headquarter of this company. Although it boosted the response rate, the location and timing of this survey might have triggered socially desirable responses in team leaders (Thompson \& Phua, 2005). This may be particularly the case in a culture like China characterized by high power distance and uncertainty avoidance (Bernardi, 2006). A social-desirability bias in team leaders would most likely result in overrating team collaboration and performance (both rated by team leaders). This would lead to an underestimation of the strength of the relationships in our model, and may explain to some extent why we found no evidence of the positive mediation path in larger teams. Future research would benefit from using more objective performance measures and from administering surveys in a context that minimizes potential social pressures.

Lastly, we only focused on leaders' positions within intrateam networks. Whereas this is important and can be studied in and of itself, leaders also have external functions (e.g., coordinating with other teams, securing management support; Ancona, 1990; Ancona \& Caldwell, 1992). The current focus on the internal network is not to deny the importance of external networks of team leaders (Druskat \& Wheeler, 2003; Mehra et al., 2006). Understanding the role of team leaders' network positions in both internal and external networks is a valuable direction for future research (Carter et al., 2015).

\section{Conclusion}

The impact of leader centrality on team performance is an important issue in understanding team leadership from the social network perspective. Our study contributes to this perspective by developing a mediated moderation model of the influence of leader network centrality. In doing so, it lays the foundations for future research to systematically map the influence of factors that reflect a team's needs for leadership - the extent to which teams face communication and coordination 
challenges, and thus stand to benefit from leaders in more central positions in team networks.

\section{Declarations}

Conflict of Interest The authors declare no competing interests.

Open Access This article is licensed under a Creative Commons Attribution 4.0 International License, which permits use, sharing, adaptation, distribution and reproduction in any medium or format, as long as you give appropriate credit to the original author(s) and the source, provide a link to the Creative Commons licence, and indicate if changes were made. The images or other third party material in this article are included in the article's Creative Commons licence, unless indicated otherwise in a credit line to the material. If material is not included in the article's Creative Commons licence and your intended use is not permitted by statutory regulation or exceeds the permitted use, you will need to obtain permission directly from the copyright holder. To view a copy of this licence, visit http://creativecommons.org/licenses/by/4.0/.

\section{References}

Agneessens, F., \& Wittek, R. (2012). Where do intra-organizational advice relations come from? The role of informal status and social capital in social exchange. Social Networks, 34(3), 333-345.

Amason, A. C., \& Sapienza, H. J. (1997). The effects of top management team size and interaction norms on cognitive and affective conflict. Journal of Management, 23(4), 495-516.

Ancona, D. G. (1990). Outward bound: Strategies for team survival in an organization. Academy of Management Journal, 33(2), 334-365.

Ancona, D. G., \& Caldwell, D. (1992). Demography and design: Predictors of new product team performance. Organization Science, 3(3), 321-341.

Babalola, M. T., Stouten, J., Euwema, M. C., \& Ovadje, F. (2018). The relation between ethical leadership and workplace conflicts: The mediating role of employee resolution efficacy. Journal of Management, 44(5), 2037-2063.

Bachrach, D. G., Lewis, K., Kim, Y., Patel, P. C., Campion, M. C., \& Thatcher, S. M. B. (2019). Transactive memory systems in context: A meta-analytic examination of contextual factors in transactive memory systems development and team performance. Journal of Applied Psychology, 104(3), 464-493.

Balkundi, P., \& Harrison, D. A. (2006). Ties, leaders, and time in teams: Strong inference about the effects of network structure on team viability. Academy of Management Journal, 49(1), 49-68.

Balkundi, P., \& Kilduff, M. (2006). The ties that lead: A social network approach to leadership. Leadership Quarterly, 17(4), 419-439.

Balkundi, P., Barsness, Z., \& Michael, J. H. (2009). Unlocking the influence of leadership network structures on team conflict and viability. Small Group Research, 40(3), 301-322.

Balkundi, P., Kilduff, M., \& Harrison, D. A. (2011). Centrality and charisma: Comparing how leader networks and attributions affect team performance. Journal of Applied Psychology, 96(6), 1209-1222.

Bedwell, W. L., Wildman, J. L., DiazGranados, D., Salazar, M., Kramer, W. S., \& Salas, E. (2012). Collaboration at work: An integrative multilevel conceptualization. Human Resource Management Review, 22(2), 128-145.

Bell, S. T., Villado, A. J., Lukasik, M. A., Belau, L., \& Briggs, A. L. (2011). Getting specific about demographic diversity variable and team performance relationships: A meta-analysis. Journal of Management, 37(3), 709-743.

Bernardi, R. A. (2006). Associations between Hofstede's cultural constructs and social desirability response bias. Journal of Business Ethics, 65(1), 43-53.

Boies, K., Fiset, J., \& Gill, H. (2015). Communication and trust are key: Unlocking the relationship between leadership and team performance and creativity. The Leadership Quarterly, 26(6), 1080-1094.

Bonacich, P. (1987). Power and centrality: A family of measures. American Journal of Sociology, 92(5), 1170-1182.

Borgatti, S. P., \& Everett, M. G. (2006). A graph-theoretic perspective on centrality. Social Networks, 28(4), 466-484.

Borgatti, S. P., \& Foster, P. C. (2003). The network paradigm in organization research: A review and typology. Journal of Management, 29(6), 991-1013.

Borgatti, S. P., Everett, M. G., \& Freeman, L. C. (2002). Ucinet for Windows: Software for social network analysis. In Harvard Analytic Technologies, 2006. SNA: Analysis software.

Borgatti, S. P., Carley, K. M., \& Krackhardt, D. (2006). On the robustness of centrality measures under conditions of imperfect data. Social Networks, 28(2), 124-136.

Borgatti, S. P., Mehra, A., Brass, D. J., \& Labianca, G. (2009). Network analysis in the social sciences. Science, 323(April), 892-896.

Brass, D. J., \& Burkhardt, M. E. (1993). Potential power and power use: An investigation of structure and behavior. Academy of Management Journal, 36(3), 441-470.

Brislin, R. W. (1970). Back-translation for cross-cultural research. Journal of Cross-Cultural Psychology, 1(3), 185-216.

Campion, M. A., Papper, E. M., \& Medsker, G. J. (1996). Relations between work team characteristics and effectiveness: A replication and extension. Personnel Psychology, 49(2), 429-452.

Carson, J. B., Tesluk, P. E., \& Marrone, J. A. (2007). Shared leadership in teams: An investigation of antecedent conditions and performance. Academy of Management Journal, 50(5), 1217-1234.

Carter, D. R., DeChurch, L. A., Braun, M. T., \& Contractor, N. S. (2015). Social network approaches to leadership: An integrative conceptual review. Journal of Applied Psychology, 100(3), 597-622.

Carton, A. M., \& Cummings, J. N. (2012). A theory of subgroups in work teams. Academy of Management Review, 37, 441-470.

Cha, J., Kim, Y., Lee, J. Y., \& Bachrach, D. G. (2015). Transformational leadership and inter-team collaboration: Exploring the mediating role of teamwork quality and moderating role of team size. Group and Organization Management, 40(6), 715-743.

Contractor, N. S., DeChurch, L. A., Carson, J. B., Carter, D. R., \& Keegan, B. (2012). The topology of collective leadership. Leadership Quarterly, 23(6), 994-1011.

Curral, L. A., Forrester, R. H., Dawson, J. F., \& West, M. A. (2001). It's what you do and the way that you do it: Team task, team size, and innovation-related group processes. European Journal of Work and Organizational Psychology, 10(2), 187-204.

Day, D. V., Gronn, P., \& Salas, E. (2006). Leadership in team-based organizations: On the threshold of a new era. Leadership Quarterly, 17(3), 211-216.

Druskat, V. U., \& Wheeler, J. V. (2003). Managing from the boundary: The effective leadership of self-managing work teams. Academy of Management Journal, 46(4), 435-457.

Friedrich, T. L., Vessey, W. B., Schuelke, M. J., Ruark, G. A., \& Mumford, M. D. (2009). A framework for understanding collective leadership: The selective utilization of leader and team expertise within networks. Leadership Quarterly, 20(6), 933-958.

Gardner, D. G., Cummings, L. L., Dunham, R. B., \& Pierce, J. L. (1998). Single-item versus multiple-item measurement scales: An empirical comparison. Educational and Psychological Measurement, 58(6), 898-915. 
Guzzo, R. A., \& Shea, G. P. (1992). Group performance and intergroup relations in organizations. In Handbook of industrial and organizational psychology (Vol. 3, pp. 269-313).

Haleblian, J., Finkelstein, S., \& Haleblian, J. (1993). Top management team size, CEO dominance, and firm performance: The moderating roles of environmental turbulence and discretion. Academy of Management Journal, 36, 844-863.

Hayat, T. (Zack), \& Mo, G. Y. (2015). Advice giving and receiving within a research network. American Behavioral Scientist, 59(5), 582-598.

Hobman, E. V., Bordia, P., \& Gallois, C. (2003). Consequences of feeling dissimilar from others in a work team. Journal of Business and Psychology, 17(3), 301-325.

Hogg, M. A., Rast, D. E., \& van Knippenberg, D. (2012). The social identity theory of leadership: Theoretical origins, Research findings, And conceptual developments. European Review of Social Psychology, 23(1), 258-304.

Hollenbeck, J. R., Ellis, A. P. J., Humphrey, S. E., Garza, A. S., \& Ilgen, D. R. (2011). Asymmetry in structural adaptation: The differential impact of centralizing versus decentralizing team decision-making structures. Organizational Behavior and Human Decision Processes, 114(1), 64-74.

Ibarra, H., \& Andrews, S. B. (1993). Power, social influence, and sense making: Effects of network centrality and proximity on employee perceptions. Administrative Science Quarterly, 38, 277-303.

Johnson, P. O., \& Neyman, J. (1936). Tests of certain linear hypotheses and their application to some educational problems. Statistical Research Memoirs, 1, 57-93.

Kearney, E., \& Gebert, D. (2009). Managing diversity and enhancing team outcomes: The promise of transformational leadership. Journal of Applied Psychology, 94(1), 77-89.

Kerr, N. L. (1989). Illusions of efficacy: The effects of group size on perceived efficacy in social dilemmas. Journal of Experimental Social Psychology, 25(4), 287-313.

Kilduff, M., \& Krackhardt, D. J. (2008). Interpersonal networks in organizations: Cognition, personality, dynamics, and culture. Cambridge University Press.

Klein, K. J., \& Kozlowski, S. W. J. (2000). From micro to meso: Critical steps in conceptualizing and conducting multilevel research. Organizational Research Methods, 3, 211-236.

Klein, K. J., Lim, B. C., Saltz, J. L., \& Mayer, D. M. (2004). How do they get there? An examination of the antecedents of centrality in team networks. Academy of Management Journal, 47(6), 952-963.

Kozlowski, S. W. J., \& Klein, K. J. (2000). A multilevel approach to theory and research in organizations: Contextual, temporal, and emergent processes. Multilevel Theory Research and Methods in Organizations Foundations Extensions and New Directions, 3-90.

Krackhardt, D. J. (1999). The ties that torture: Simmelian tie analysis in organizations. In Research in the Sociology of Organizations (Vol. 16, pp. 183-210).

Kratzer, J., Leenders, R. T. A. J., \& Van Engelen, J. M. L. (2008). The social structure of leadership and creativity in engineering design teams: An empirical analysis. Journal of Engineering and Technology Management, 25(4), 269-286.

Latané, B., Williams, K., \& Harkins, S. (1979). Many hands make light the work: The causes and consequences of social loafing. Journal of Personality and Social Psychology, 37(6), 822-832.

Lee, P., Gillespie, N., Mann, L., \& Wearing, A. (2010). Leadership and trust: Their effect on knowledge sharing and team performance. Management Learning, 41(4), 473-491.

Leenders, R. T. A. J., van Engelen, J. M. L., \& Kratzer, J. (2003). Virtuality, communication, and new product team creativity: A social network perspective. Journal of Engineering and Technology Management, 20(1), 69-92.

LePine, J. A., Piccolo, R. F., Jackson, C. L., Mathieu, J. E., \& Saul, J. R. (2008). A meta-analysis of teamwork processes: Tests of a multidimensional model and relationships with team effectiveness criteria. Personnel Psychology, 61(2), 273-307.

MacKinnon, D. P., Lockwood, C. M., \& Williams, J. (2004). Confidence limits for the indirect effect: Distribution of the product and resampling methods. Multivariate Behavioral Research, 39(1), 99-128.

Marks, M. a., Mathieu, J. E., \& Zaccaro, S. J. (2001). A temporally based framework and taxonomy of team processes. Academy of Management Review, 26(3), 356-376.

Mehra, A., Kilduff, M., \& Brass, D. J. (2001). The social networks of high and low self-monitors: Implications for workplace performance. Administrative Science Quarterly, 46(1), 121-146.

Mehra, A., Dixon, A. L., Brass, D. J., \& Robertson, B. (2006). The Social network ties of group leaders: Implications for group performance and leader reputation. Organization Science, 17(1), 64-79.

Mohammed, S., \& Nadkarni, S. (2011). Temporal diversity and team performance: The moderating role of team temporal leadership. Academy of Management Journal, 54(3), 489-508.

Morgeson, F. P., DeRue, D. S., \& Karam, E. P. (2010). Leadership in teams: A functional approach to understanding leadership structures and processes. Journal of Management, 36(1), 5-39.

Nederveen Pieterse, A., Hollenbeck, J. R., van Knippenberg, D., Spitzmüller, M., Dimotakis, N., Karam, E. P., \& Sleesman, D. J. (2019). Hierarchical leadership versus self-management in teams: Goal orientation diversity as moderator of their relative effectiveness. Leadership Quarterly, 30(6), 101343.

Nicolaides, V. C., LaPort, K. A., Chen, T. R., Tomassetti, A. J., Weis, E. J., Zaccaro, S. J., \& Cortina, J. M. (2014). The shared leadership of teams: A meta-analysis of proximal, distal, and moderating relationships. Leadership Quarterly, 25(5), 923-942.

Oh, H., Chung, M.-H., \& Labianca, G. (2004). Group social capital and group effectiveness: The role of informal socializing ties. Academy Of Management Journal, 47, 860-875.

Pan, W., Zhao, P., \& Ding, X. (2019). The effects of network structure on research innovation: an analysis from a content perspective using the data of R\&D funding. Technology Analysis \& Strategic Management, 31(12), 1430-1446.

Pearce, C. L., \& Herbik, P. A. (2004). Citizenship behavior at the team level of analysis: The effects of team leadership, team commitment, perceived team support, and team size. The Journal of Social Psychology, 144(3), 293-310.

Peeters, M. A. G., van Tuijl, H. F. J. M., Rutte, C. G., \& Reymen, I. M. M. J. (2006). Personality and team performance: A meta-analysis. European Journal of Personality, 20(5), 377-396.

Peltokorpi, V., \& Hasu, M. (2014). How participative safety matters More in team innovation as team size increases. Journal of Business and Psychology, 29(1), 37-45.

Perry-Smith, J. E. (2006). Social yet creative: The role of social relationships in facilitating individual creativity. Academy of Management Journal, 49(1), 85-101.

Poulton, B. C., \& West, M. A. (1999). The determinants of effectiveness in primary health care teams. Journal of Interprofessional Care, 13(1), 7-18.

Preacher, K. J., Curran, P. J., \& Bauer, D. J. (2006). Computational tools for probing interactions in multiple linear regression, multilevel modeling, and latent curve analysis. Journal of Educational and Behavioral Statistics, 31(4), 437-448.

Reagans, R., \& Zuckerman, E. W. (2001). Networks, diversity, and productivity: The social capital of corporate R\&D teams. Organization Science, 12(4), 502-517.

Rossiter, J. R. (2008). Content validity of measures of abstract constructs in management and organizational research. British Journal of Management, 19(4), 380-388.

Rousseau, D. M., \& Tijoriwala, S. A. (1998). Assessing psychological contracts: Issues, alternatives and measures. Journal of Organizational Behavior, 19, 679-695. 
Shin, S. J., \& Zhou, J. (2007). When is educational specialization heterogeneity related to creativity in research and development teams? Transformational leadership as a moderator. Journal of Applied Psychology, 92(6), 1709-1721.

Soltis, S. M., Agneessens, F., Sasovova, Z., \& Labianca, G. J. (2013). A Social network perspective on turnover intentions: The role of distributive justice and social support. Human Resource Management, 52(4), 561-584.

Sparrowe, R. T., \& Liden, R. C. (2005). Two routes to influence: Integrating leader-member exchange and social network perspectives. Administrative Science Quarterly, 50(4), 505-535.

Sparrowe, R. T., Liden, R. C., Wayne, S. J., \& Kraimer, M. L. (2001). Social networks and the performance of individuals and groups. Academy of Management Journal, 44(2), 316-325.

Steffens, N. K., Haslam, S. A., Reicher, S. D., Platow, M. J., Fransen, K., Yang, J., Ryan, M. K., Jetten, J., Peters, K., \& Boen, F. (2014). Leadership as social identity management: Introducing the Identity Leadership Inventory (ILI) to assess and validate a four-dimensional model. Leadership Quarterly, 25(5), 1001-1024.

Stewart, G. L. (2006). A meta-analytic review of relationships between team design features and team performance. Journal of Management, 32(1), 29-55.

Stewart, G. L., Courtright, S. H., \& Manz, C. C. (2019). Self-leadership: A paradoxical core of organizational behavior. Annual Review of Organizational Psychology and Organizational Behavior, 6, 47-67.

Tan, J. C. (2015). Package 'probemod'. R Package Version, 0.2.1.

Thompson, E. R., \& Phua, F. T. T. (2005). Reliability among senior managers of the Marlowe-Crowne short-form social desirability scale. Journal of Business and Psychology, 19(4), 541-554.

Tingley, D., Yamamoto, T., Hirose, K., Keele, L., \& Imai, K. (2014). Mediation: R package for causal mediation analysis. Journal of Statistical Software, 59(5), 1-38.

Tröster, C., Mehra, A., \& van Knippenberg, D. (2014). Structuring for team success: The interactive effects of network structure and cultural diversity on team potency and performance. Organizational Behavior and Human Decision Processes, 124(2), 245-255.

Uzzi, B., \& Spiro, J. (2005). Collaboration and creativity: The small world problem. American Journal of Sociology, 111(2), 447-504.

van Dick, R., Lemoine, J. E., Steffens, N. K., Kerschreiter, R., Akfirat, S. A., Avanzi, L., Dumont, K., Epitropaki, O., Fransen, K., Giessner,
S., González, R., Kark, R., Lipponen, J., Markovits, Y., Monzani, L., Orosz, G., Pandey, D., Roland-Lévy, C., Schuh, S., Sekiguchi, T., Song, L. J., Stouten, J., Tatachari, S., Valdenegro, D., van Bunderen, L., Vörös, V., Wong, S. I., Zhang, X. A., \& Haslam, S. A. (2018). Identity leadership going global: Validation of the identity leadership inventory across 20 countries. Journal of Occupational and Organizational Psychology, 91(4), 697-728.

van Knippenberg, D. (2017). Team leadership. In The Wiley Blackwell Handbook of the Psychology of Team Working and Collaborative Processes (pp. 345-368). Wiley.

van Knippenberg, D., \& Mell, J. N. (2016). Past, present, and potential future of team diversity research: From compositional diversity to emergent diversity. Organizational Behavior and Human Decision Processes, 136, 135-145.

van Knippenberg, D., De Dreu, C. K. W., \& Homan, A. C. (2004). Work group diversity and group performance: An integrative model and research agenda. Journal of Applied Psychology, 89(6), 1008-1022.

Venkataramani, V., Zhou, L., Wang, M., Liao, H., \& Shi, J. (2016). Social networks and employee voice: The influence of team members' and team leaders' social network positions on employee voice. Organizational Behavior and Human Decision Processes, 132, $37-$ 48.

Wang, D., Waldman, D. A., \& Zhang, Z. (2014). A meta-analysis of shared leadership and team effectiveness. Journal of Applied Psychology, 99(2), 181-198.

Wong, S. S. (2004). Distal and local group learning: Performance tradeoffs and tensions. Organization Science, 15(6), 645-656.

Zaccaro, S. J., Rittman, A. L., \& Marks, M. A. (2001). Team leadership. The Leadership Quarterly, 12(4), 451-483.

Zagenczyk, T. J., \& Murrell, A. J. (2009). It is better to receive than to give: Advice network effects on job and work-unit attachment. Journal of Business and Psychology, 24(2), 139-152.

Zhu, Y. Q., Gardner, D. G., \& Chen, H. G. (2018). Relationships between work team climate, individual motivation, and creativity. Journal of Management, 44(5), 2094-2115.

Publisher's Note Springer Nature remains neutral with regard to jurisdictional claims in published maps and institutional affiliations. 